\title{
Pseudorabies Virus Propagated in Rabbit Kidney-Derived RK13 Cells is Neutralized by Natural IgM Antibodies in Normal Swine Serum which Specifically Lyse Host Cells
}

\author{
Sunao HAYASHI ${ }^{1)}$, Yasuhiro TAKASHIMA ${ }^{1,2) *}$ and Haruki OTSUKA ${ }^{1)}$ \\ ${ }^{1)}$ Department of Global Animal Resource Science, Graduate School of Agricultural and Life Sciences, The University of Tokyo, 1-1-1 \\ Yayoi, Bunkyo-ku, Tokyo 113-8657 and ${ }^{2)}$ Department of Veterinary Parasitological Diseases, Gifu University, 1-1 Yanagito, Gifu 501- \\ 1193, Japan
}

(Received 7 March 2003/Accepted 8 November 2004)

\begin{abstract}
Pseudorabies virus (PRV) propagated in rabbit kidney-derived RK-13 cells (PRV-RK) was neutralized by serum obtained from specific pathogen-free pigs through the activation of complement. The virus-neutralizing activity of swine serum was lost after treatment with ethylene glycol-bis-aminoethylether-N,N,N',N'-tetraacetic acid (EGTA) or ethylenediaminetetraacetic acid (EDTA). Anti-C1q and anti-IgM antibodies also inhibited virus-neutralizing activity. Though IgG-depleted swine serum neutralized PRV, IgM and IgG-free swine serum lost virus-neutralizing activity. Pre-incubation of swine serum with RK-13 cells, but not with swine kidney-derived CPK cells, at $4^{\circ} \mathrm{C}$ eliminated the virus-neutralizing activity to PRV-RK. Results indicated that swine serum contained natural IgM against an antigen(s) on the RK-13 cell surface and that this surface antigen was integrated into the PRV envelope during the budding process. Thus the natural IgM in swine serum reacted with the RK-13 antigen on the viral envelope, activated the complement cascade and neutralized the PRV-RK.
\end{abstract}

KEY WORDS: complement, natural antibodies, PRV.

J. Vet. Med. Sci. 67(3): 229-234, 2005

We previously reported that pseudorabies virus (PRV) grown in rabbit kidney-derived RK-13 cells was neutralized by swine serum while the same virus grown in porcine kidney-derived CPK cells was resistant [17]. However, the virus-neutralizing activity of swine serum was lost when serum was heat-inactivated at $56^{\circ} \mathrm{C}$ for $30 \mathrm{~min}$. We speculated that neutralization of PRV was caused by activation of complement via the alternative pathway because of the apparent absence of anti-PRV antibodies in swine serum [17]. We also found that a similar phenomenon was observed when PRV grown in several cell lines was incubated with human serum [13]. PRV grown in several cell lines also showed different resistant levels against rabbit serum [13].

It has been known that human immunodeficiency virus type 1 acquires cell membrane complement regulatory factors on its envelope from cells during the budding process, thereby escaping from complement attack [18]. Therefore it was assumed that RK-13-grown PRV acquired complement regulatory factors from the host rabbit cells and these were less effective against swine complement attack. On the other hand PRV grown in CPK cells acquired swine complement regulatory factors which are more effective regulators against swine complement and thus were resistant to swine complement attack [17].

However, further study revealed that RK-13 cells were lysed by swine serum via the activation of complement clas-

\footnotetext{
* Correspondence to: TAKashima, Y., Laboratory of Veterinary Parasitological Diseases, Department of Veterinary Medicine, Faculty of Applied Biological Sciences, Gifu University 1-1 Yanagito, Gifu 501-1193, Japan.
}

sical pathway (Hayashi et al., in preparation). It was found that swine serum contained natural IgM antibodies that specifically reacted with an antigen or antigens on the RK-13 cell surface. Therefore a question arose whether the antiRK-13 natural IgM in swine serum is responsible for the neutralization of PRV grown in RK-13 cells.

In this study, using swine serum and PRV propagated in RK-13 cells (PRV-RK), we investigated the mechanism for the virus-neutralizing activity of normal serum on viruses grown in other animal-derived cells and demonstrated that swine natural IgM antibodies reacted with an antigen or antigens on the PRV envelope, which was derived from RK13 cells, and this activated the classical pathway of complement.

\section{MATERIALS AND METHODS}

Cells and viruses: Rabbit kidney-derived RK-13 and porcine kidney-derived CPK cells were cultured in Eagle's minimum essential medium (E-MEM, Nissui, Tokyo, Japan) supplemented with $7.5 \%$ heat-inactivated fetal calf serum (FCS) and $60 \mu \mathrm{g} / \mathrm{m} l$ kanamycin. Two strains of PRV, PRV (BUK-dl3) and PRV (dlg92dltk), were described earlier $[15,16]$. PRV (BUK-d13) was a thymidine kinase deletion mutant derived from the Bucharest strain of PRV. PRV (dlg92dltk) was derived from PRV (BUK-dl3) with a deletion in the $\mathrm{gC}$ gene. These viruses were propagated in $\mathrm{CPK}$ cells and kept at $-80^{\circ} \mathrm{C}$ in our laboratory. Before using these viruses for experiments in this study, these viruses were once propagated in RK-13 cells (PRV-RK and PRVdlgC-RK were obtained by propagating PRV(BUK- 
dl3) or PRV(dlg92dltk) in RK-13 cells, respectively).

Sera: Blood samples were obtained from specific pathogen free (SPF) pigs (age 6 months, Zen-noh Institute of Animal Health, Chiba, Japan) and from healthy Japanese White strain rabbits. Blood samples were allowed to clot at room temperature for $60 \mathrm{~min}$, and pooled sera were aliquoted and stored at $-80^{\circ} \mathrm{C}$. Neither swine nor rabbit sera used in this study contained antibodies against PRV by ELISA or virusneutralization tests.

Reagents and antibodies: Goat anti-human complement C1q antiserum was purchased from Sigma (Saint Louis, MO). Affinity-purified goat antibody against swine $\operatorname{IgM}(\mu$ specific) and peroxidase-labeled goat anti-swine IgM ( $\mu$ specific) were purchased from Kirkegaard \& Perry Laboratories Inc. (Gaitherburg, MD). Peroxidase-labeled rabbit anti-swine $\operatorname{IgG}(\mathrm{H}+\mathrm{L}$-specific) was purchased from ZYMED Laboratories, Inc. (San Francisco, CA). Polyclonal mouse antisera against RK-13 or CPK cells were prepared as previously described [17].

Plaque-titration of PRV: CPK cells were grown in 24 well plates and incubated at $37^{\circ} \mathrm{C}$ until monolayers were formed. Medium was removed from the wells, and virus suspension was added at $0.1 \mathrm{~m} l$ per well. After $1 \mathrm{hr}$ incubation at $37^{\circ} \mathrm{C}$ to permit adsorption, the monolayers were overlaid with E-MEM containing $0.5 \%$ methylcellulose and $1 \%$ FCS. Plaques were allowed to develop for 2 days, fixed with $99.5 \%$ ethanol, stained with $0.15 \%$ crystal violet, and counted.

Complement virus neutralization assay (CVN assay): A $300 \mu l$ reaction mixture contained about 300 PFU of PRVCPK, PRV-RK, PRVdlgC-CPK or PRVdlgC-RK, swine or rabbit serum as a source of complement, $20 \mathrm{mM}$ HEPES buffer, and E-MEM supplemented with $1 \%$ heat-inactivated FCS. The reaction mixtures were incubated at $37^{\circ} \mathrm{C}$ for $1 \mathrm{hr}$, and the surviving virus was plaque-titrated using 3 wells of CPK cell monolayers. To examine the inhibitory effect of anti-swine $\mathrm{IgM}$ or anti-human $\mathrm{C} 1 \mathrm{q}$ antibodies, they were incubated with swine serum at $4^{\circ} \mathrm{C}$ for $1 \mathrm{hr}$. These sera were used in the CVN assay as described above.

Calcium and magnesium ions in swine serum were chelated by adding ethylenediaminetetraacetic acid (EDTA) at a final concentration of $10 \mathrm{mM}$. Calcium ion alone was chelated in $10 \mathrm{mM}$ ethylene glycol-bis-aminoethylether$\mathrm{N}, \mathrm{N}, \mathrm{N}$ ', N'-tetraacetic acid (EGTA) containing $2 \mathrm{mM}$ $\mathrm{MgCl}_{2}$. With the CVN assays using these chelated sera, $3 \times$ $10^{4} \mathrm{PFU}$ of PRV-RK or PRVdlgC-RK were incubated with these sera at $37^{\circ} \mathrm{C}$ for $1 \mathrm{hr}$, and the reaction mixture was diluted 1:100 with E-MEM and then plaque-titrated using 3 wells of CPK cell monolayers.

Pre-absorption of swine serum with cells: A $500 \mu \mathrm{l}$ reaction mixture containing $20 \%$ swine serum and $2.5 \times 10^{7} \mathrm{RK}$ 13 or CPK cells in phosphate buffered saline (PBS) was incubated on ice for $1 \mathrm{hr}$ and centrifuged, and the cell-free supernatant serum was used in the CVN assay.

Preparation of IgG-depleted swine serum: One $\mathrm{m} l$ of swine serum was applied to a pre-packed protein A column (HITrapTM protein A HP, Amersham Biosciences, Upp- sala, Sweden) and eluted with PBS. The pass-through fractions were pooled, aliquoted, and stored at $-80^{\circ} \mathrm{C}$.

Preparation of rabbit anti-swine IgM antibodies: Fifteen $\mathrm{m} l$ of saturated ammonium sulfate was added drop-wise to $30 \mathrm{ml}$ swine serum, and this was kept at $4^{\circ} \mathrm{C}$ for $2 \mathrm{hr}$ and centrifuged at $10,000 \times \mathrm{g}$ for $30 \mathrm{~min}$. The supernatant was discarded, and precipitates were dissolved in $10 \mathrm{~m} l \mathrm{PBS}$ and centrifuged at $10,000 \times \mathrm{g}$ for $30 \mathrm{~min}$. The supernatant was applied to a Bio-Gel A-0.5m gel (Bio-Rad Laboratories, Hercules, CA $)$ column $(2.5 \times 90 \mathrm{~cm})$ and eluted with PBS. The fractions containing IgM were located by ELISA test using peroxidase-labeled goat anti-swine $\operatorname{IgM}$ ( $\mu$-specific) (data not shown). These fractions were then pooled, concentrated by ultra-filtration by a centrifugal filter device (ULTRAFREE-15, MILLIPORE, Bedford, MA), and rechromatographed by the same Bio-Gel A- $0.5 \mathrm{~m}$ column. The IgM fractions were pooled and used for immunizing rabbits.

New Zealand white rabbits were immunized with $1.5 \mathrm{mg}$ of swine IgM with complete Freund's adjuvant per rabbit and 3 weeks later with Freund's incomplete adjuvant. Two more boosters were given at two weeks intervals with the same amount of swine IgM with Freund's incomplete adjuvant. One week after the final immunization, blood samples were collected from the rabbits, and rabbit anti-swine IgM sera were prepared.

Preparation of protein A bead antibody affinity column: Rabbit anti-swine IgM antibody was immobilized on protein A beads according to Gersten and Marchalonis [11]. Briefly, $2 \mathrm{ml}$ of rabbit anti-swine IgM serum was mixed with $2 \mathrm{ml}$ suspension of protein A-Sepharose 4B beads (SIGMA, St. Louis, MO), and this was incubated at room temperature for $1 \mathrm{hr}$ with gentle rocking. The beads were washed twice with $10 \mathrm{~m} l$ of $0.2 \mathrm{M}$ sodium borate buffer $(\mathrm{pH}$ 9.0) and re-suspended in $10 \mathrm{~m} l$ of the same buffer. To the suspension, solid di-methylpimelimidate was added to bring the final concentration to $20 \mathrm{mM}$, and this was mixed for 30 min at room temperature. The reaction was stopped by washing the beads once in $0.2 \mathrm{M}$ ethanolamine $(\mathrm{pH} \mathrm{8.0)}$, and this was then incubated for $2 \mathrm{hr}$ at room temperature in 0.2 $M$ ethanolamine.

Preparation of IgM and IgG-depleted swine serum: Protein A beads coupled with rabbit anti-swine IgM antibodies as described above were poured into a small column to a bed volume of $1.5 \mathrm{~m} l$ and washed extensively with PBS. To the top of the column, $0.5 \mathrm{~m} l$ of swine serum was applied, and this was eluted with PBS. The pass-through protein fraction was collected, aliquoted, stored at $-80^{\circ} \mathrm{C}$, and thawed immediately before use as a source of $\operatorname{IgM}$ and $\operatorname{IgG}$-depleted swine serum. The fraction was checked for the absence of anti-swine IgG or IgM antibodies by ELISA test (data not shown).

\section{RESULTS}

Characterization of the virus-neutralizing mechanism of swine serum: Previously we demonstrated that PRV propa- 
A

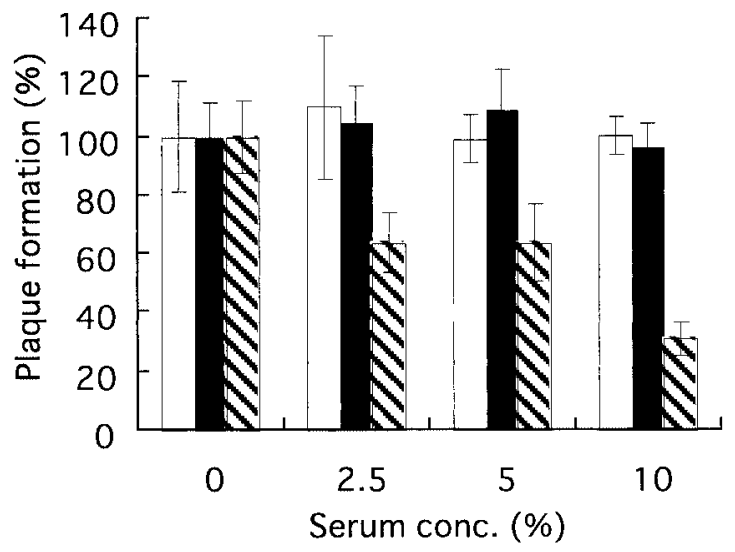

B

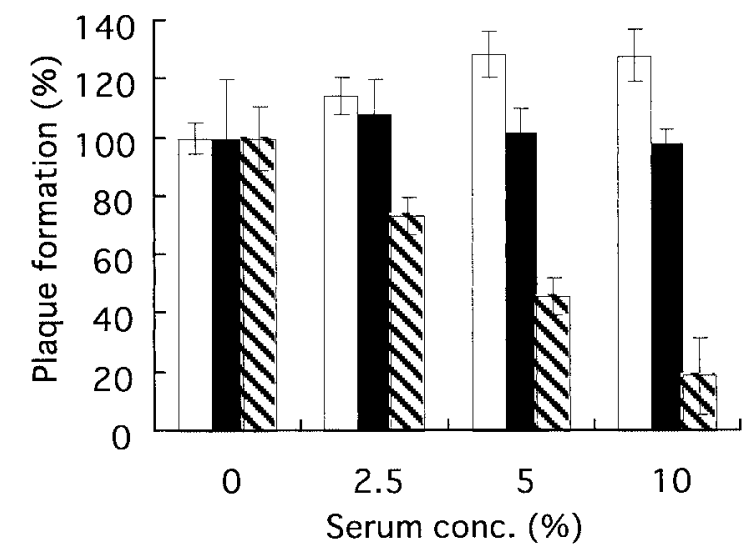

Fig. 1. Effect of EGTA and EDTA on the virus-neutralizing effect of swine serum on PRV-RK (A) or PRVdlgC-RK (B). To inactivate both classical and alternative complement pathways, EDTA was added to swine serum at a final concentration of 10 $\mathrm{mM}$. To inactivate only the classical complement pathway, 10 mM EGTA and $2 \mathrm{mM} \mathrm{MgCl}_{2}$ were added. Viruses were incubated with 0 to $10 \%$ swine serum pre-treated with EDTA or EGTA at $37^{\circ} \mathrm{C}$ for $1 \mathrm{hr}$ and then plaque titrated. The survival rate was calculated as the percentage of the number of plaques of the control (the same virus incubated without serum). Vertical lines represent S.D.

gated in RK-13 cells was neutralized by normal swine serum. Since this virus-neutralizing activity was eliminated by heating the serum at $56^{\circ} \mathrm{C}$ for $30 \mathrm{~min}$, it was assumed that the activation of complement was responsible for the virusneutralizing activity [17]. To determine whether the virusneutralizing effect of swine serum was activated via the complement classical pathway or the alternative pathway, PRV-RK and PRVdlgC-RK were reacted with swine sera pretreated with EDTA or EGTA. It has been known that both $\mathrm{Mg}^{2+}$ and $\mathrm{Ca}^{2+}$ ions are required to activate the classical pathway of complement, while $\mathrm{Mg}^{2+}$ but not $\mathrm{Ca}^{2+}$ is required to activate the alternative pathway. Therefore EDTA blocks both pathways, and EGTA (in the presence of $\mathrm{Mg}^{2+}$ ) blocks only the classical pathway [5]. As shown in Fig. 1, 70\% of PRV-RK and $80 \%$ of PRVdlgC-RK were neutralized by $10 \%$ normal swine serum as compared with control $(0 \%$

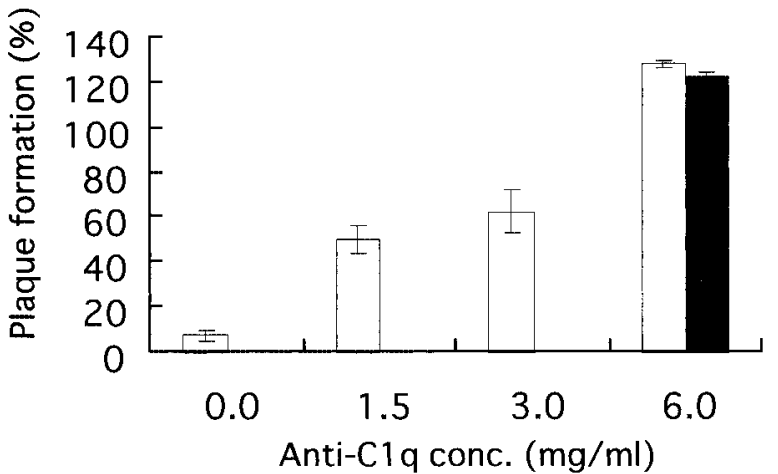

Fig. 2. Effect of anti-human $\mathrm{C} 1 \mathrm{q}$ antibody on the sensitivity of PRV-RK to swine serum. Swine serum was incubated with 0 to $6 \mathrm{mg} / \mathrm{ml}$ of goat anti-human $\mathrm{Clq}$ antibody at $4^{\circ} \mathrm{C}$ for $30 \mathrm{~min}$., and viruses were then added to the mixture. The final concentration of the serum is $10 \%$. Survival rate was calculated as described in Fig. 1. To check the toxicity of anti-C1q antibody, viruses were mixed with $6 \mathrm{mg} / \mathrm{m} l$ of anti-C1q antibody in the absence of serum.

serum concentration). On the other hand, EDTA or EGTA treatment completely eliminated the virus-neutralizing effect of swine serum against PRV-RK (Fig. 1A) and PRVdlgC-RK (Fig. 1B). Therefore it can be speculated that the virus-neutralizing activity of swine serum was due to the activation of the classical pathway of complement.

To further confirm that the virus-neutralizing activity of swine serum was due to the activation of the classical pathway of complement, the effect of anti-C1q antibody was tested in the CVN assay. Complement component $\mathrm{C} 1$ is a large, multimeric protein complex composed of $\mathrm{C} 1 \mathrm{q}, \mathrm{C} 1 \mathrm{r}$, and $\mathrm{C} 1 \mathrm{~s}$ subunits. $\mathrm{C} 1$ binds to two or more Fc portions of antibody that has bound antigen and initiates the complement classical pathway [19]. Figure 2 shows the effect of anti-human C1q antibody on the virus-neutralizing activity of swine serum against PRV-RK (Fig. 2) in the presence of $10 \%$ swine serum. Addition of anti-C1q antibodies decreased the virus-neutralizing activity of swine serum in a dose-dependent manner. Although the anti-C1q antibody used in this study was anti-human C1q, it was confirmed that this antibody cross-reacted with swine $\mathrm{Clq}$ molecule by Western blot analysis (data not shown).

IgM antibodies as the activator of the classical pathway: Since the classical pathway of complement activation is triggered by either IgG or IgM antibodies, swine serum must contain IgG or IgM which specifically reacts with PRV-RK or PRVdlgC-RK. Previous study revealed that normal swine serum contains natural IgM antibodies that react specifically with RK-13 cells and activate the classical pathway of complement (Hayashi et al., in preparation). It may be possible that the virus-neutralizing activity of swine serum against PRV-RK or PRVdlgC-RK uses the same natural IgM antibodies against RK-13 cells. This assumption was confirmed by the observation that after incubating swine serum with anti-swine $\operatorname{IgM}(\mu)$ antibody at $4{ }^{\circ} \mathrm{C}$, swine 
A

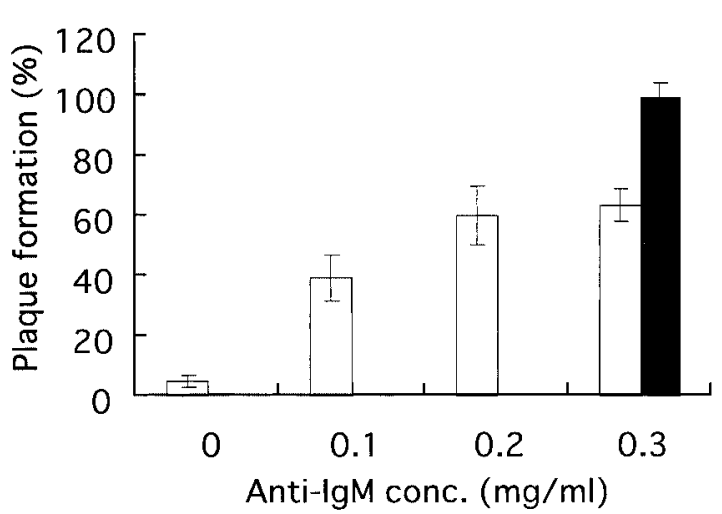

$\mathrm{B}$

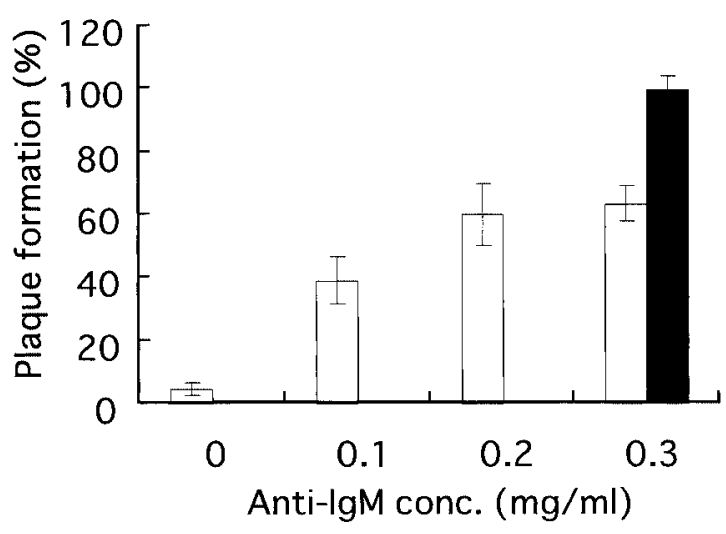

Fig. 3. Effect of anti-swine IgM antibody on the sensitivity of PRV-RK (A) or PRVdlgC-RK (B) to swine serum. Swine serum was incubated with 0 to $0.3 \mathrm{mg} / \mathrm{m} l$ of anti-swine IgM antibody at $4^{\circ} \mathrm{C}$ for $30 \mathrm{~min}$, and viruses were then added to the mixture. The final concentration of the serum is $10 \%$. Survival rate was calculated as described in Fig. 1. To check the toxicity of antiIgM antibody, viruses were mixed with $0.3 \mathrm{mg} / \mathrm{m} l$ of anti-IgM antibody in the absence of serum.

serum lost its virus-neutralizing activity against PRV-RK and PRVdlgC-RK. As shown in Fig. 3, anti-swine IgM antibody protects PRV-RK (Fig. 3a) and PRVdlgC-RK (Fig. $3 b)$ from neutralization by swine serum. Since the antiswine $\operatorname{IgM}(\mu)$ antibody used in this study did not react with swine IgG, contribution of IgG to the virus-neutralizing effect of swine serum seemed to be negligible. Indeed IgGdepleted swine serum still retained the virus-neutralizing effect (Fig. 4).

IgM and IgG antibodies were depleted from swine serum by using an affinity column as described in Materials and Methods. As shown in Fig. 5, IgM, IgG-depleted swine serum completely lost its virus-neutralizing activity against PRV-RK and PRVdlgC-RK. To check whether this IgM, IgG-depleted serum still retained complement components for the classical pathway, CPK cells sensitized by mouse anti-CPK antibody were incubated with this serum (data not shown). It was found that the IgM, IgG-depleted swine serum contained complement components for the classical
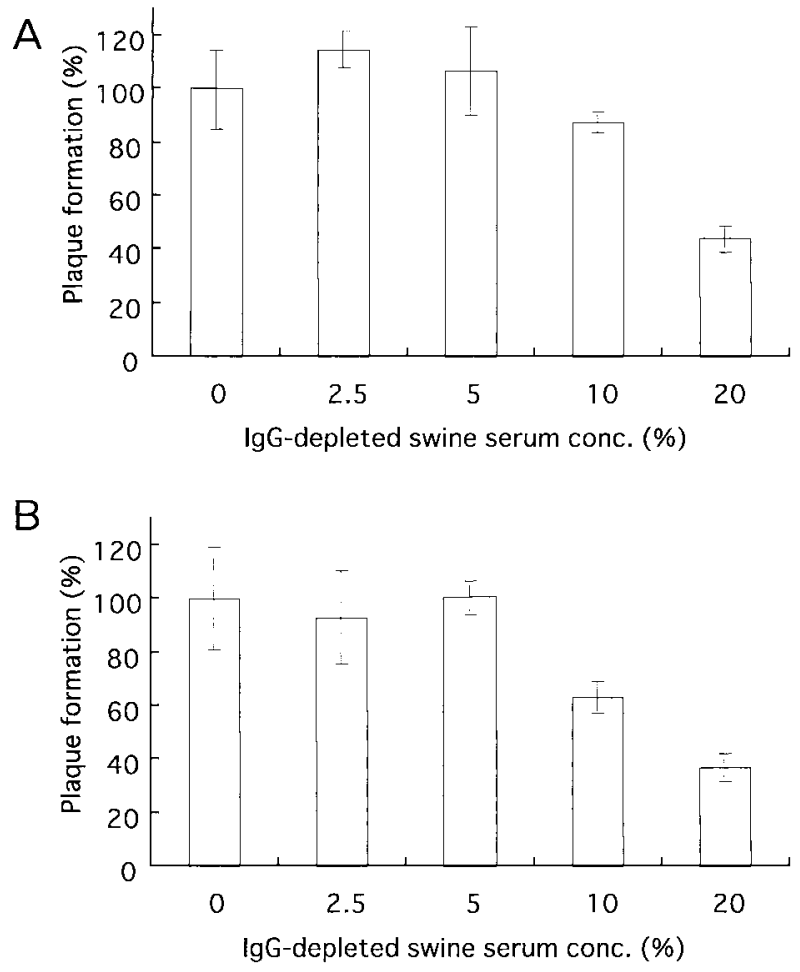

Fig. 4. Virus-neutralizing effect of IgG-depleted swine serum on PRV-RK (A) or PRVdlgC-RK (B). Viruses were incubated with 0 to $20 \%$ IgG-depleted swine serum at $37^{\circ} \mathrm{C}$ for $1 \mathrm{hr}$. Survival rate was calculated as described in Fig. 1.

pathway (data not shown).

The effect of pre-absorption of swine serum with $R K-13$ or CPK cells: When RK-13 cells were incubated with swine serum at $4^{\circ} \mathrm{C}$, no cytotoxicity was observed. At this temperature IgM was absorbed onto the cell surface, but complement was not activated (data not shown). Swine serum was incubated with RK-13 or CPK cells at $4^{\circ} \mathrm{C}$ in order to remove IgM that has affinity to RK-13 or CPK cells. The cell-free supernatant was tested for virus-neutralizing activity against PRV-RK or PRVdlgC-RK at $37^{\circ} \mathrm{C}$. As shown in Fig. 6, swine serum pre-treated with RK-13 cells lost its virus-neutralizing activity to PRV-RK. On the other hand, swine serum pre-treated with CPK did not lose its neutralizing activity to PRV-RK (Fig. 6a). The same results were observed when PRVdlgC-RK were incubated with each serum (Fig. 6b).

\section{DISCUSSION}

Electron microscopic analysis of alphaherpesviruses revealed that after intranuclear assembly, nucleocapsids bud at the inner leaflet of the nuclear membrane, resulting in enveloped particles in the perinuclear space. Egress from the perinuclear cisterna occurs by fusion of the primary envelope with the outer leaflet of the nuclear membrane. The resulting intracytoplasmic naked nucleocapsids acquire 
A

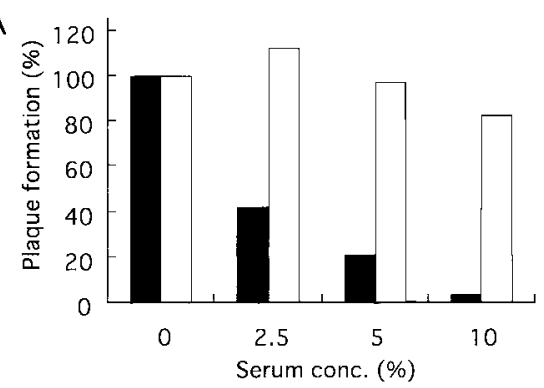

B

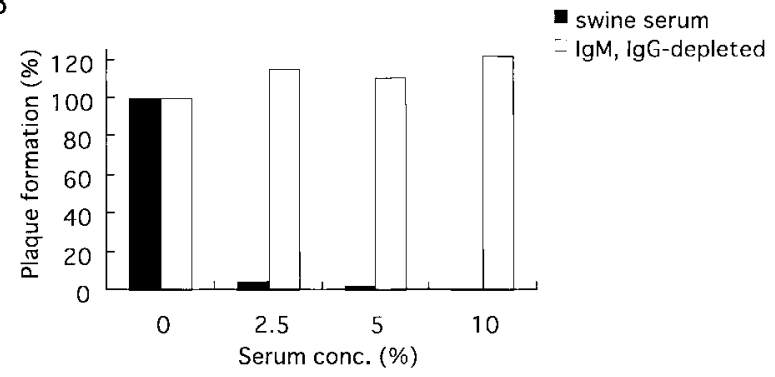

Fig. 5. Virus-neutralizing effect of IgM, IgG-depleted swine serum on PRV-RK (A) or PRVdlgC-RK (B). Viruses were incubated with 0 to $10 \%$ IgM, IgG-depleted swine serum at $37^{\circ} \mathrm{C}$ for $1 \mathrm{hr}$. Survival rate was calculated as described in Fig. 1.

their final envelope downstream in the secretory pathway $[2,4,10,12]$. Indeed, our previous study revealed that purified PRV-RK virion contains not only its envelope glycoprotein $\mathrm{gC}$ but also RK-13 cellular proteins [17]. Moreover, it was suggested that RK-13 cells were lysed by normal swine IgM antibodies via classical complement pathway (Hayashi et al., in preparation). Therefore, it is probable that the herpesvirus envelope contains some components of the cellular membrane. In this study, we found that natural IgM in swine serum reacted with PRV-RK, activated complement via the classical pathway, and neutralized virus. The fact that swine serum loses its virus-neutralizing activity by pre-exposing serum to RK-13 cells suggests that the same antigen(s) on the surface of RK-13 cells exists on the envelope of PRV-RK. This antigen(s) on the viral envelope is the target of the natural IgM antibodies in swine serum. Since PRV grown in CPK cells (PRV-CPK, PRVdlgC$\mathrm{CPK}$ ) did not contain the RK-13 cell surface antigen, the natural IgM in swine serum did not react with PRV-CPK particles, and thus PRV-CPK was not neutralized by swine serum (data not shown). PRV-CPK may contain CPK cellderived complement regulatory factors in the viral envelope, but these probably play only a minor role in resisting the neutralizing effect of swine serum.

It is known that the $\alpha$-gal epitope is a common carbohydrate structure identified on the surface of cells of almost all mammals except Old World primates and the anti- $\alpha$-gal epitope natural antibodies exist in the normal serum of Old World primates including humans [19]. We prepared PRV
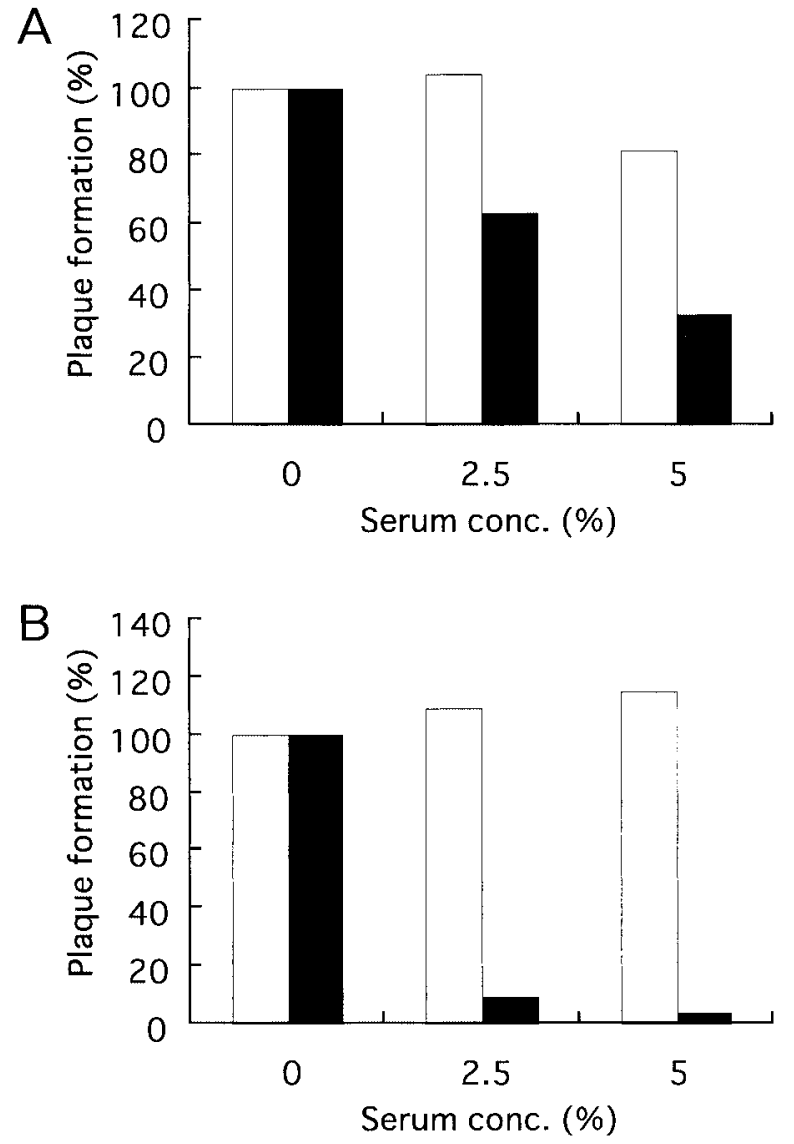

Fig. 6. The effect of pre-absorbing swine serum with RK13 or CPK cells on PRV-RK (A) or PRVdlgC-RK (B). Swine serum was incubated with RK13 or CPK cells at $4^{\circ} \mathrm{C}$ for $1 \mathrm{hr}$, and 0 to $5 \%$ of the cell-free supernatant serum was tested for virus-neutralizing activity against PRV-RK or PRVdlgC-RK at $37^{\circ} \mathrm{C}$. Survival rate was calculated as described in Fig. 1.

grown in cells with no- or low-level expression of $\alpha$-gal epitope such as Vero cells (PRV-Vero). Though PRV-CPK was neutralized by normal human serum, PRV-Vero was not neutralized. ELISA was carried out using purified PRVCPK and PRV-Vero virions, $\alpha$-gal epitopes were detected on PRV-CPK virion, and neither on PRV-Vero [13]. In the same way, it is suggested that PRV-RK virion also contains the natural IgM epitope on its envelope. Although the reaction of anti- $\alpha$-gal epitope natural antibodies to PRV-CPK was directly proved by ELISA [13], we failed to detect the natural IgM in swine serum reacting to PRV-RK by ELISA, Western blotting analysis and immuno-precipitation (data not shown). So far we don't know the reason of the failure. The effect may not be due to antibodies reacting with only one epitope as like the anti $\alpha$-gal antibodies but due to sum of many different antibodies, of which epitopes also varied. The amount of each natural IgM in swine serum reacting PRV-RK might be much less than that of anti- $\alpha$-gal epitope natural antibody. 
It would appear that the lysis of RK-13 cells and the neutralization of PRV-RK by swine serum are triggered by the same antigen(s) and natural IgM antibodies, but the mechanisms for cell lysis and virus neutralization by complement may be different. It has commonly been known that cell lysis by complement is due to the formation of a membrane attack complex (MAC). Cell-associated C5 convertase cleaves $\mathrm{C} 5$ and generates $\mathrm{C} 5 \mathrm{~b}$, which becomes bound to the convertase. $\mathrm{C} 6$ and $\mathrm{C} 7$ bind sequentially, and the $\mathrm{C} 5 \mathrm{~b}, 6,7$ complex becomes directly inserted into the lipid bilayer of the plasma membrane, followed by stable insertion of $\mathrm{C} 8$. Up to $15 \mathrm{C} 9$ molecules may then polymerize around the complex to form pores in the membrane [1]. On the other hand, Friedman et al. demonstrate that complement component $\mathrm{C} 8$ and terminal lytic activity are not required to neutralize herpes simplex virus type 1 (HSV-1) [8]. Our preliminary experiments also indicated that virus neutralization by natural IgM did not require the formation of MAC (data not shown). It may be possible that deposition of $\mathrm{C} 3$ on virus particles, triggered by natural IgM, is enough to abolish the infectivity of PRV.

It has been known that glycoprotein $\mathrm{C}(\mathrm{gC})$ of alphaherpesviruses, such as HSV-1, serves as an inhibitor of activation of the complement cascade by binding complement component $\mathrm{C} 3 \mathrm{~b}$ and by blocking the binding of properdin and $\mathrm{C} 5$ to $\mathrm{C} 3 \mathrm{~b}[3,6,7,14]$. Although statistical differences were not detected, the gC-deletion mutant PRVdlgC-RK was always more sensitive to $10 \%$ swine serum treatment (Figs. 1, 2, 3 and 5). It may be due to the effect of the deletion of $\mathrm{gC}$.

ACKNOWLEDGEMENT. This work was supported by the grants from the Ministry of Education, Science, Sports and Culture of Japan.

\section{REFERENCES}

1. Abbas, A. K., Lichtman, A. H. and Pober, J. S. 2000. pp. 316330, Cellular and Molecular Immunology. 4th ed., W. B. Saunders Company, Philadelphia.

2. Cheung, P., Banfield, B. W. and Tufaro, F. 1991. Brefeldin A arrests the maturation and egress of herpes simplex virus particles during infection. J. Virol. 65: 1893-1904.

3. Eisenberg, R. J., Ponce de Leon, M., Friedman, H. M., Fries, L. F., Frank, M. M., Hastings, J. C. and Cohen, G. H. 1987. Complement component $\mathrm{C} 3 \mathrm{~b}$ binds directly to purified glycoprotein $\mathrm{C}$ of herpes simplex virus types 1 and 2. Microb. Pathog. 3: 423-435.

4. Elliott, G. and O'Hare, P. 1999. Live-cell analysis of a green fluorescent protein-tagged herpes simplex virus infection. $J$. Virol. 73: 4110-4119.

5. Fine, D. P., Marney, S. R., Jr., Colley, D. G., Sergent, J. S. and Des Prez, R. M. 1972. C3 shunt activation in human serum chelated with EGTA. J. Immunol. 109: 807-809.

6. Friedman, H. M., Cohen, G. H., Eisenberg, R. J., Seidel, C. A. and Cines, D. B. 1984. Glycoprotein C of herpes simplex virus 1 acts as a receptor for the $\mathrm{C} 3 \mathrm{~b}$ complement component on infected cells. Nature (Lond.) 309: 633-635.

7. Friedman, H. M., Glorioso, J. C., Cohen, G. H., Hastings, J. C., Harris, S. L. and Eisenberg, R. J. 1986. Binding of complement component $\mathrm{C} 3 \mathrm{~b}$ to glycoprotein $\mathrm{gC}$ of herpes simplex virus type 1: mapping of gC-binding sites and demonstration of conserved $\mathrm{C} 3 \mathrm{~b}$ binding in low-passage clinical isolates. J. Virol. 60: $470-475$.

8. Friedman, H. M., Wang, L., Pangburn, M. K., Lambris, J. D. and Lubinski, J. 2000. Novel mechanism of antibody-independent complement neutralization of herpes simplex virus type 1 . J. Immunol. 165: 4528-4536.

9. Galili, U. 1993. Evolution and pathophysiology of the human natural anti- $\alpha$-galactosyl natural antibody. Springer Semin. Immunopathology 15: 155-171.

10. van Genderen, I. L., Brandimarti, R., Torrisi, M. R., Campadelli, G. and van Meer, G. 1994. The phospholipid composition of extracellular herpes simplex virions differs from that of host cell nuclei. Virology 200: 831-836.

11. Gersten, D. M. and Marchalonis, J. J. 1978. A rapid, novel method for the solid-phase derivatization of IgG antibodies for immune-affinity chromatography. J. Immunol. Methods 24: 305-309.

12. Granzow, H., Klupp, B. G., Fuchs, W., Veits, J., Osterrieder, N. and Mettenleiter, T. C. 2001. Egress of alphaherpesviruses: comparative ultrastructural study. J. Virol. 75: 3675-3684.

13. Hayashi, S., Takashima, Y., Ogawa, S. and Otsuka, H. 2003. The neutralization of pseudorabies virus by anti-alpha-galactosyl natural antibody in normal human serum. Virus Res. 99: 17.

14. Huemer, H. P., Larcher, C. and Coe, N. E. 1992. Pseudorabies virus glycoprotein III derived from virions and infected cells binds to the third component of complement. Virus Res. 23: 271-280.

15. Kit, S., Sheppard, M. and Kit, M. 1986. Control of Aujeszky's disease. Vet. Rec. 118: 310.

16. Kit, S., Sheppard, M., Ichimura, H. and Kit, M. 1987. Secondgeneration pseudorabies virus vaccine with deletions in thymidine kinase and glycoprotein genes. Am. J. Vet. Res. 48: 780793.

17. Maeda, K., Hayashi, S., Tanioka, Y., Matsumoto, Y. and Otsuka, H. 2002. Pseudorabies virus (PRV) is protected from complement attack by cellular factors and glycoprotein $\mathrm{C}(\mathrm{gC})$. Virus Res. 84: 79-87.

18. Marschang, P., Sodroski, J., Wurzner, R. and Dierich, M. P. 1995. Decay-accelerating factor (CD55) protects human immunodeficiency virus type 1 from inactivation by human complement. Eur. J. Immunol. 25: 285-290.

19. Prodinger, W. M., Wurzner, R., Erdei, A. and Dierich, M. P. 1999. Complement. pp. 967-995. In: Fundamental Immunology, 4th ed. (William E. P. ed.), Lippincott-Raven Publisher, Philadelphia. 